\title{
Assessment of Direct and Indirect Factors Affecting the Nutrition Status of Hostel Girls in Pantnagar (India)
}

\author{
Shweta Joshi ${ }^{1}$ and Archana Kushwaha ${ }^{2 *}$ \\ ${ }^{1}$ Department of Home Science/ Food Technology, BFIT Institute, Sudhowala, \\ Dehradun, Uttarakhand, India \\ ${ }^{2}$ Department of Foods and Nutrition, College of Home Science, GBPUA\&T, \\ Pantnagar, Uttarakhand, India
}

*Corresponding author

\begin{abstract}
A B S T R A C T
Nutritional status of girl students is of more importance as they are future mothers and the food choices they make had a major effect on their health. The main aim of the study was to assess the direct and indirect factors affecting the nutritional status of girls residing in hostel of GBPUA\&T,

\section{Keywords}

Hostel girls, Nutrition status, Dietary adequacy, Knowledge, Attitude, Practice, Physical activity

\section{Article Info}

Accepted:

10 July 2019

Available Online:

10 August 2019

Pantnagar, and Uttarakhand which include the assessment of dietary intake using 24 hour recall method, anthropometric measurements, assessment of food habits, knowledge, attitude and practice. For the purpose 100 girls from university hostel were selected. The diet of girls was found adequate in protein $(81 \%)$, fat $(88 \%)$, calcium $(78 \%)$, iron $(76 \%)$, ascorbic acid $(95 \%)$ and zinc $(80 \%)$ with regard to RDA except beta carotene which was only 16 percent adequate with respect to RDA. Regarding nutrient adequacy fat intake of the respondents was 88 percent adequate whereas protein was found to be 87.63 per cent adequate and energy value of the respondents were found to be 80.25 per cent adequate which indicates that their nutrient intake was fairly adequate. Consumption of fast food was very high among hostel girls. Data regarding skipping of meals indicates that majority (45\%) of girls skip breakfast than other meals and 83 percent of the respondents were influenced by their likes and dislikes while choosing their food. Regarding their knowledge, attitude and practice, 60 per cent of the girls possess good knowledge and 81 percent carry right attitude regarding nutrition but only 8 percent practice good nutrition habits. Data on level of physical activity reveals that 68 per cent of the hostel girls were indulged in different kinds of physical activity. Thus the study indicates that the dietary adequacy of girls was fairly good but frequent consumption of fast among girls put them forward towards various lifestyle diseases.
\end{abstract}

\section{Introduction}

Our health and well-being, quality of life and ability to learn, work and play depend on how well we are nourished.

Good nutrition or nutritional status is the outcome of many direct and indirect factors. Direct factors such as access to adequate, safe, affordable and nutritious food, adequate intake of all the food groups, dietary habits, the food choices they make, whereas the indirect factors effecting the nutritional status are their knowledge, attitude and practice regarding nutrition and healthy eating, socio economic status and life style practices like physical activity are some of the unavoidable factors that affect the level of nutrition. 
For the higher education most of the students live in hostels and hostel life has strong impact on the health (Eikhalifa et al., 2000). Boys and girl students who are living at homes their parents look after them well but hostel students especially University students are totally dependent on themselves (Popivanova et al., 1994). This age group is most vulnerable with respect to nutrition demand. Students reside at different places other than home and they make many food choices for themselves. Nutritional status of girl students is of more importance as they are future mothers and the food choices they make had a major effect on their health (Richard et al., 2005). Also, eating behavior can affect long term health. Unhealthy eating habits such as skipping breakfast and excessive intake of foods with high carbohydrate and fat contents are the main factors causing nutritional problems. Students living away from home developed more unfavorable eating habits than students living at the family home. Nutritional concerns are of less

relevance to hostlers than taste and cost and it was shown that for students importance of nutrition disappears as a perception while convenience emerges (Betts et al., 1997; Glanz et al., 1998; Lappalainen et al., 1998). University hostel life may be 2 years to 6 years, during this period, students pass over the importance of diet, they usually take different types of snacks and drinks but do not take proper food, and due to this they lose their health. Inspite of healthy eating, the importance of physical activity cannot be ignored. Physical activity is important during the growth years, as most of girls residing in hostel are in growing stage. These forms of activity contribute also to mental health by offering opportunities, first, to express aggressions that do not find an outlet because of restrictions of college, second, to be constructive or creative, and third to relax and thus ease the tensions created by everyday living.
Thus the present study aims to investigate in depth the knowledge, attitudes and practices of hostel girls towards nutrition, their dietary habits, and their physical activity level and to explore the factors that affect their choices regarding food.

\section{Materials and Methods}

The study was conducted at Govind Ballabh Pant University of Agriculture and Technology, Pant nagar, Uttarakhand. There are total 22 hostels in the University campus out of which 9 hostels are for girl students. All the nine girls' hostels were selected for study. A list of room no was procured from each hostel and using random number table rooms were selected. One respondent will be selected from each selected room. From 8 hostels 11 girls were selected and from one hostel 12 girls were selected to make a total of 100 samples for study purpose. Interview Schedule was built and pilot study was done for pretesting of tool. The interview schedule was divided in to 6 sections. The first section includes the general information about the respondent and anthropometric measurements like height, weight, BMI and waist to hip ratio. Second section deals with information pertaining to dietary intake among adolescent girls using 24 hour recall method and food frequency questionnaire on fast food. Information pertaining to their food habits was gathered. Third section deals with the information pertaining to consumption of fast food, Frequency (again assessed to cross check the information given by girls in food frequency questionnaire), time and place of fast food consumption and information regarding skipping of meals was assessed. Fourth section includes the questions pertaining to factors affecting food choices among hostel girls. Questions on assessment of knowledge, attitude and practice regarding nutrition were done in fifth section and in last section level of physical activity were assessed. 


\section{Results and Discussion}

\section{General information and anthropometric measurements}

Persual of the Table 1 indicates that maximum $(52 \%)$ of the respondents fall under the age group of 21- 23 years, whereas only $6 \%$ of girls were under the age group of 18- 20 years. Regarding their education level $55 \%$ of the girls were pursuing graduation as half of the girls hostels are for graduate level girls only 3 hostels are for PG girls so the percentage of graduation girls was more in the study. Occupational status of their parents indicate that majority $(52 \%)$ of the respondents father were service man where as $4 \%$ of the father were ex- employee or retired means they are not currently doing any kind of job. Analysis of Table 1 indicates that only $22 \%$ of the respondents mother were doing job whereas $78 \%$ were housewife.

Amount of pocket money received and spent on food items

Adolescent children receiving pocket money from parents had great influence in their eating habits which in turn affect their general health thus it is suggested by the results of study that Parents and teachers play a major role in motivating adolescents on healthy spending of their pocket money (Punitha et al., 2014). Pocket money received by the hostel girls a wide ranges from Rs 500-5000 per month. Majority (38\%) of the respondents gets an amount that ranges between Rs 16002000/ month followed by Rs 2600-3000/ month, whereas only $2 \%$ of the respondents receive the amount ranging between Rs 41005000 on monthly basis. The data regarding the money spent per month on food items out of the pocket money they receive reveals that maximum $(52 \%)$ of the respondents spent Rs 900-1100 on food items on food items, whereas $4 \%$ of the girls spent Rs 100-200 per month food items. The data indicates that majority of the girls spent half of their pocket money on consumable items.

\section{Anthropometric measurements}

The anthropometric measurements were taken to get an idea about the nutritional status of the girls and for the purpose height, weight were measured for calculating Body mass index (BMI). The BMI of the girls as indicated in Table 2 reveals that 59 per cent of the girls were under normal category which indicates that the nutritional status of the girls was fairly satisfactory. It was found that 4 percent, 1 percent and 15 percent of the respondents fall under the chronic energy deficiency grade I, II and III respectively and only 10 per cent of the respondents were found to be under obese category. Anthropometry is the measurement of body height, weight \& proportions. It is an essential component of clinical examination and used to evaluate both under \& over nutrition. The measured values reflects the current nutritional status (Gorstein and Akré 1988)

The waist to hip ratio of the hostel girls was also measured and it was found that mean waist to hip ratio of the girls was found to be 0.79 which approximately is equal to 0.8 which is considered a normal range for girls and the data indicates that the girls are free from abdominal obesity.

\section{Dietary intake and food habits}

\section{Food habit}

The result regarding food habits revealed that majority $(54 \%)$ of the girls follow non vegetarian diet where as 24 percent were found to be ova- vegetarian and 22 percent were pure vegetarians. The hostels of University follow 4 time meal pattern so accordingly the categories were made. Persual 
of Table 3 indicates that frequency of food consumption of half of the girls was 3 times a day, whereas 44 percent take their meals 4 times a day and 6 percent of the girls partake their meals only 2 times a day which indicates that most of the girls are regular in their meals. Food habits of a person indicate his way of selecting food. Factors that guide food choice include taste preference, sensory attributes, cost, availability, convenience, cognitive restraint, and cultural familiarity (Warren, 2008).

Role of nutrients is crucial during the reproductive age of girls. Poor nutrition during this period has a lifelong impact on health. Data regarding the dietary intake was assessed using 24 hour recall method for one day. Energy, protein, fat calcium, iron, carotene, ascorbic acid and zinc were taken in to consideration. The mean energy value of girls was $1789.68 \mathrm{Kcal} /$ day which was 94 per cent adequate with respect to RDA as shown in figure 1 and 2 . There diet was also found adequate in protein and fat i.e. 81 and 88 percent respectively. Regarding minerals the mean intake of calcium, iron and zinc was $468 \mathrm{mg}, 16 \mathrm{mg}$ and $8 \mathrm{mg}$ respectively as shown in Figure 1 which was found adequate with respect to RDA. Minerals several vital functions in the body like calcium is important accelerated muscular, skeletal, and endocrine development and this period represents a "window of opportunity" for optimal bone development and future health (Nix, S. 2009). Iron serves as a carrier of oxygen to the tissues, act as a transport medium for electrons within cells, and as an integrated part of important enzyme systems in various tissues whereas zinc is needed for the body's defensive (immune) system to properly work. It plays a role in cell division, cell growth, wound healing (Kaewruang, 2010). Among vitamins ascorbic acid and beta carotene were assessed and vitamin $\mathrm{C}$ intake was found adequate i.e. 95 per cent but adequacy of beta carotene in their diet was very poor. Only 16 percent of RDA for beta carotene was supplied to body through their diet. These vitamins also had to play important roles in body along with the anti-oxidant properties.

\section{Fast food consumption}

The data on fast food indicates that consumption of fast food was very high among hostel girls. Out of 100 respondents 98 girls were found to consume fast food whereas only 2 respondents denied consuming fast food as indicated in Table 3. It was found that majority $(70 \%)$ consume fast food at evening hour's i.e after 5:00 pm, after college time. Ten percent of the respondents reported consumption of fast food during free time between their lectures, whereas $8 \%$ of the girls consume fast food during their lunch time.

Data regarding the place where the respondents often enjoy their fast food were found to have multiple responses means they opted more than one option but the highest priority $(82 \%)$ of the respondents like to relish their fast food in Badi market, where as 52 percent responses were in favour of university canteens and 40 percent responses indicated hostel mess for relishing fast food during evening tea.

\section{Frequency and type of fast food consumption}

The data on frequency of fast food consumption indicates that only 1 percent of the respondent was found to have daily consumption of fast food whereas maximum (44\%) of the respondents enjoy fast food on weekly basis. The data regarding the fast food consumption indicates that even though majority of the respondents consume fast food but they were not addicted to it as we can see that the consumption is mainly on weekly 
basis and even 12 percent of the respondents were found to consume fast food on monthly basis, whereas 2 percent reported consumption of fast food occasionally.

The frequency of fast food consumption is here again asked to crosscheck whether the frequency with which they introduced previously was correct or not and here also type of fast food consumed was also asked to know the choices of girls regarding the fast food. The data revealed that among the type of fast foods Chinese foods (Maggie, chowmein, springrolls), Fried foods (golgappe, samosa, chips, tikki, chat) and steamed (momos) were mostly consumed. Chinese food items were consumed on weekly basis by 50 percent respondents

Table.1 General Information

\begin{tabular}{|c|c|}
\hline Variables & Percentage (\%) \\
\hline Age Group (years) & 6 \\
$\mathbf{1 8 - 2 0}$ & 52 \\
$\mathbf{2 1 - 2 3}$ & 31 \\
$\mathbf{2 4 - 2 6}$ & 11 \\
$\mathbf{2 7 - 2 9}$ & \\
Level of education & 55 \\
Pursuing Graduation & 30 \\
Pursuing Masters & 15 \\
Pursuing Ph. D & \\
\hline Occupational status of Parents & \\
Fathers occupation & 52 \\
Service man & 44 \\
Businessman & 4 \\
Ex- employee(retired) & \\
Mothers occupation & 78 \\
Housewife & 22 \\
Servicewomen & \\
\hline
\end{tabular}

Table.2 Body mass index of hostel girls

\begin{tabular}{|c|c|c|}
\hline BMI & Presumptive Diagnosis & \% of girls \\
\hline$<\mathbf{1 6}$ & CED Grade -3(severe) & 4 \\
\hline $\mathbf{1 6}-\mathbf{1 7}$ & CED Grade-2(moderate) & 1 \\
\hline $\mathbf{1 7 - 1 8 . 5}$ & CED Grade-1(mild) & 15 \\
\hline $\mathbf{1 8 . 5 - 2 0 . 0}$ & Low weight -normal & 11 \\
\hline $\mathbf{2 0 . 0 - 2 5 . 0}$ & Normal & 59 \\
\hline $\mathbf{2 5 . 0 - 3 0 . 0}$ & Obese grade- 1 & 7 \\
\hline$<\mathbf{3 0 . 0}$ & Obese grade- 2 & 3 \\
\hline
\end{tabular}

$\mathrm{CED}=$ Chronic energy deficiency 
Table.3 Consumption of fast food among hostel girls

\begin{tabular}{|c|c|}
\hline Variables & \% of girls $(\mathbf{N}=\mathbf{1 0 0})$ \\
\hline Fast food consumption & \\
Consume fast food & 98 \\
Do not consume fast food & 2 \\
\hline Usual timing of consuming fast food & $(\mathbf{N}=\mathbf{9 8})$ \\
Free timing between lectures & 10 \\
Lunch time & 8 \\
In evening & 70 \\
\hline Usual place of eating fast food & \\
Badi market & $\mathbf{8 2}^{*}$ \\
*niversity canteens & $\mathbf{7 3}^{*}$ \\
Hostel & $\mathbf{4 0}^{*}$ \\
\hline
\end{tabular}

Table.4 Reasons of skipping meals

\begin{tabular}{|c|c|}
\hline Skipping of meals & \% of girls \\
\hline Reason of skipping breakfast (N=45) & \\
\hline Wake up late & 28 \\
Don't like & 3 \\
Too fatty & 8 \\
Repetition of same item & 5 \\
During examination & 1 \\
\hline Reason of skipping lunch (N=7) & 1 \\
Don't like & 2 \\
To control dietary intake & 3 \\
Due to heavy breakfast & 1 \\
\hline Due to lab work & \\
\hline Reason of skipping dinner (N=4) & 1 \\
Don't like & 3 \\
\hline To control dietary intake & \\
\hline
\end{tabular}

Table.5 Factors affecting food choices

\begin{tabular}{|c|c|}
\hline Factors & \% of girls $^{\text {* }}$ \\
\hline Affected by friends choice & 30 \\
\hline Influenced by family culture & 48 \\
\hline Likes and dislikes & 83 \\
\hline Influenced by media & 22 \\
\hline Effected by mood & 79 \\
\hline Body image consciousness & 53 \\
\hline Effected by mess bill & 13 \\
\hline
\end{tabular}

$*=\%$ values are based on multiple responses 
Table.6 Knowledge, attitude and practice regarding nutrition

\begin{tabular}{|c|c|}
\hline Knowledge level & \% of girls $(\mathbf{N}=\mathbf{1 0 0})$ \\
\hline Excellent & 7 \\
Good & 60 \\
Average & 28 \\
Poor & 5 \\
\hline Attitude & \\
\hline Right attitude & 81 \\
Wrong attitude & 19 \\
\hline Practice & 8 \\
\hline Practice nutrition & 92 \\
\hline
\end{tabular}

Table.7 Level of physical activity

\begin{tabular}{|c|c|}
\hline Category & \%of girls \\
\hline Perform physical activity & 68 \\
Do not perform physical activity & 32 \\
\hline Type of physical activity & $(\mathbf{N}=\mathbf{6 8})$ \\
Jogging & 12 \\
Exercise & 18 \\
Cycling & 8 \\
Outdoor games & 28 \\
Dancing & 2 \\
\hline Frequency & 38 \\
Daily & 22 \\
Weekly & 8 \\
\hline Once in a month & \\
Duration & 30 \\
1 hour & 25 \\
30 minutes & 8 \\
2 hours & 5 \\
\hline Less than half an hour & \\
\hline
\end{tabular}

Fig.1 Dietary intake and nutrient adequacy with respect to RDA

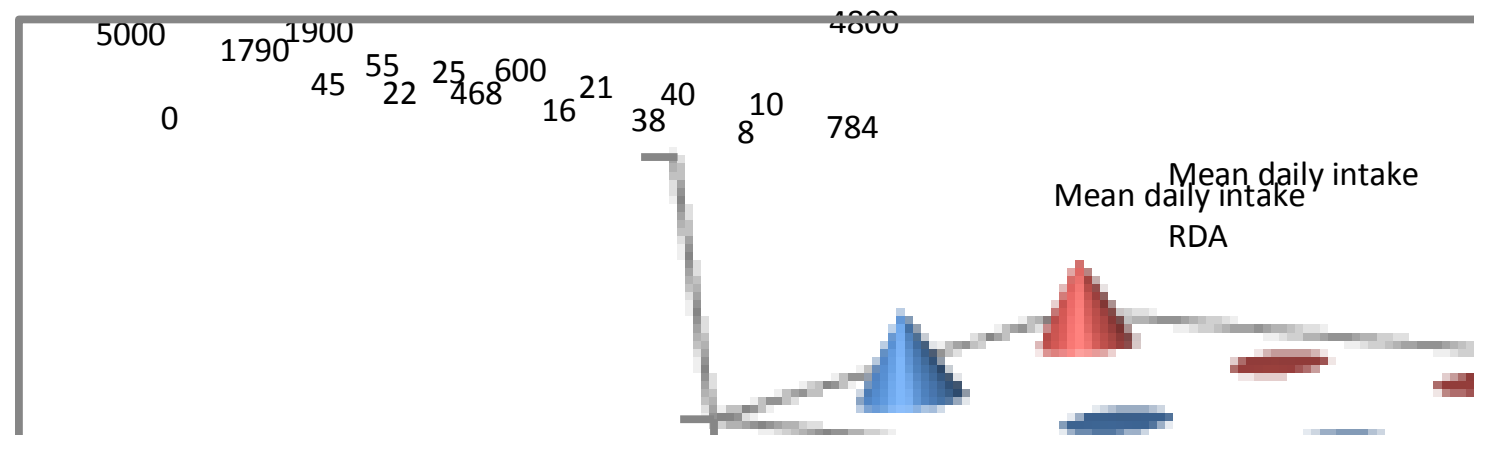


Fig.2 Dietary adequacy of girls with respect to RDA

\section{Dietary adequacy with respect to RDA(\%)}

94

81
88

78
95

80

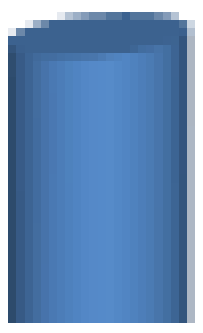

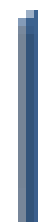

\section{Skipping of meals among hostel girls}

Data regarding the skipping of meals also contradicts with the frequency of consumption which indicates that majority of the girls were regular in their meal intake but the perusal of Table 4 indicates that maximum $(56 \%)$ of the respondents skip meals whereas $44 \%$ of the girls are found regular in their meal intake. Among the meals majority, 45\% skip breakfast. Whereas 7 percent skip lunch and only 4 percent found to skip dinner. Unhealthy eating habits such as skipping breakfast and excessive intake of foods with high carbohydrate and fat contents are the main factors causing nutritional problems. Hostel students often do not have sufficient knowledge and experience to make appropriate decisions, and tend to develop unhealthy eating habits. These habits include skipping breakfast, replacing lunch meals with snack foods, and increasing soft drink intake, all of which can lead to inadequate nutrient intake (Betts et al., 1997).
Reasons regarding skipping of meals were asked and Table 4 indicates that maximum (28\%) of the respondents skip breakfast because they wake up late in the morning. Eight percent found breakfast too fatty, five percent skip breakfast as same item is repeated daily whereas 3 percent did not like breakfast and 1 percent reported to skip breakfast only during examinations.

Among the reasons of skipping lunch it was found that 3 percent respondents skip lunch due to heavy breakfast, two percent skip to control their dietary intake, whereas 1 percent of the respondents do not like lunch and another 1 percent indicated that due to lab work they had to skip their lunch.

For dinner 3 percent of the respondents indicated they had a feeling of satiety so they skip dinner, whereas 1 percent indicated their disliking towards dinner. So skipping meals was found common among hostel girls of the university. 
Factors affecting food choices among hostel girls

To know the psychological reasons or influencing factors regarding choosing of food among the hostel girls the data was collected as these factors directly or indirectly effects the dietary intake of the girls which further influences their nutritional status.

The Table 5 indicates multi categorical responses of the girls as more than one factor can influence their food choice. The data indicates that 83 percent which is the maximum percentage of the respondents, choose their food which is influenced by their likes and dislikes means the food which they found tasty are liked by them whether it carries some nutrition value or not.

Seventy nine percent of the girls food choice was effected by their mood followed by 53 percent which were conscious about their body image so they choose food accordingly, whereas 48 percent of the respondents food choice is effected by their family culture which indicates that these girls prefer only those foods which are consumed and liked by their family members. Thirty percent of the girls are influenced by their friends on choosing their food, whereas 22 percent were influenced by advertisements for making their food choices and only 13 percent are found to be effected by their mess bill in choosing their food means when they found that their mess bill is high they usually omit the food which they found costly.

In hostel life young boys and girls neglect the importance of nutrition. There is a big issue of malnutrition, food available at canteens usually cooked in unhygienic condition and usually during the process of cooking most of the essential nutrients will destroy and food will not fulfill the requirement of students (Fatima et al., 2011).

\section{Knowledge, attitude and practice regarding nutrition among hostel girls}

The perusal of Table 6 indicates that maximum $(60 \%)$ of the respondents possess good knowledge regarding nutrition followed by 28 percent having average knowledge. Only 7 percent were found to give correct answers of all the questions based on nutrition knowledge, whereas 5 percent of the respondents were under poor knowledge category. Food and nutritional knowledge has been demonstrated to have positive effect on the quality of dietary intake as well as healthy food purchasing behaviour among adults. Improvements of nutrition knowledge, by exposing an individual to new information possibly arouse changes in attitude and consequently resulting in improvements in dietary behaviour (Vriendt, 2009).

Analysis of Table 6 indicates that 81 percent of girls possess right attitude regarding nutrition whereas nineteen percent the girls possess wrong attitude with respect to nutrition. The percentage of girls having wrong attitude show their disagreement with the statements like, inclusion of pulses in our daily diet provides good amount of protein necessary for our body, consumption of fast food is a major problem especially among hostlers and they were agree with the statement that consumption of ready to eat foods are convenient, easily available, cheap so their consumption should be more and they also consider dieting as a good practice to avoid obesity. In contrast with the attitude data perusal of Table 6 indicates that only 8 percent respondents practice the attitude they carry about good nutrition whereas 92 percent respondents do not practice nutrition as most of them do not take their meal regularly, they do not include fruits in their daily diet, eat fast food very frequently and they spent their pocket money more on ready to eat foods as they are cheaper and easily available as 
compared to fruits and other healthy foods. A cross-sectional university-based study was conducted by Aung et al., (2012) with the aim of investigating knowledge, attitude, and practice of healthy eating among students and to find the influencing factors on healthy eating practice of the students. The results revealed that knowledge on healthy eating of the students was not satisfactory. Only one third of the students knew the recommended daily serving size of fruits, six basic nutrients could be listed by $16.8 \%$ and only $2.2 \%$ could mention food groups to be taken as per Food Guide Pyramid. Attitude of the respondents towards given statements on healthy eating was satisfactory as a whole. Practice of taking unhealthy drinks and fried foods was still prevailing among the students.

\section{Physical activity}

Analysis of Table 7 indicates that majority $(68 \%)$ of the girls were indulged in different kinds of physical activity whereas $32 \%$ of the respondents do not perform any kind of physical activity or perform very rarely. Among different types of physical activity majority $(28 \%)$ of the respondents play outdoor games like volleyball and badminton whereas $18 \%$ of the girls reported to do different types of exercises. Jogging was done by $12 \%$ of the respondents whereas $8 \%$ do cycling and $2 \%$ enjoy dancing as a part of physical activity. Thirty eight percent of the girls perform physical activity on daily basis whereas $22 \%$ perform on weekly basis and $8 \%$ of the girls do physical activity on monthly basis and regarding the duration maximum of the respondents perform the physical activity for 1 hour. Inspite of healthy eating, the importance of physical activity cannot be ignored. Physical activity is important during the growth years, as most of girls residing in hostel are in growing stage. These forms of activity contribute also to mental health by offering opportunities, first, to express aggressions that do not find an outlet because of restrictions of college, second, to be constructive or creative, and third to relax and thus ease the tensions created by everyday living (Barooah, 2012).

The respondents under the study were the girls residing in university hostels with majority of them were pursuing graduation. Nutritional status of the hostel girls was found good with respect to their anthropometric measurements and nutrient adequacy. Fast food consumption was high among the hostlers whereas consumption of fruits and nuts was low as they found the fast food more convenient, easily available and cheaper than fruits and nuts. various psychological factors among hostel girls were found while selecting their food or during making their food choices like peer group influence, likes and dislikes, mood which indirectly effect their nutritional status. Girls posses good knowledge regarding nutrition as well as they were found to have right attitude towards nutrition but practicing this right attitude was found to be poor among them which indicates that they are well aware about the importance of nutrition but are very much ignorant while practicing them. Most of the girls were also found indulged in various kind of physical activity which further indicates that are well aware about the benefits of physical activity to carry a healthy life.

\section{References}

Aravind, G., Mondal, S., Gandhi, A., Arora, S. and Bhattacharjee, J. (2011). Effect of integrated yoga practices on immune responses in examination stress-A preliminary study. International Journal of Yoga. 4: 26-32.

Aung, P.P., Foung, C.S., Azman, K.B., Zulkifeli, N.A.B. and Hong, Y.S. (2012). Knowledge, Attitude, and Practice of Healthy Eating Among the 
$1^{\text {st }}$ and $2^{\text {nd }}$ Year Students of University Malaysia Sarawak (UNIMAS). International Conference on Nutrition and Food Sciences. 39: 188-194.

Barooah. P. (2012). Adolescents' Nutrition, Attitudes and Practices. Basic, Applied \& Social Sciences. 2: 308-311.

Betts, N.M., Amos, R.J., Keim, K., Peters, P. and Stewart, B (1997). Ways young adults view food. Journal of Nutrition Education. 29, 73 - 79.

Eikhalifa, A.M.O., Godbi, S. and Mohammed, S. (2000). Nutritional assessment of students in university hostel. Journal of Ahfad. 17: 33-44.

Fatimah, A.G., Salehuddin, M., Zahari, M., Ramli, N., Jusoff, K., Madina, Z., Zaini, M., Hamid, M., Samsudin, A., Glanz, K., Basil, M., Maibach, E., Goldberg, J. and Snyder, D. (1998). Why Americans eat what they do: taste, nutrition, cost, convenience, and weight control concerns as influences on food consumption. Journa $l$ of American Dietetic Association. 98: $1118-1126$.

Fatimah, A.G., Salehuddin, M., Zahari, M., Ramli, N., Jusoff, K., Madina, Z., Zaini, Hamid, M., Samsudin, A., Ngali, N. and Rahmat, N. (2011). Service at UiTM Residential Hostel Cafeterias-Is it Satisfactory? World Applied Science Journal. 12: 08-13

Gorstein, J. and Akré, J. (1988). The use of anthropometry to assess nutritional status. World Health Stat Q. 41(2): 4858.

Kaewruang, (2010). http://www.live strong.com/article/436094-what-role- do-micronutrients-play-in-the-body/. Lappalainen, R., Kearney, J. and Bibney, M. (1998): A pan EU survey of consumer attitudes to food, nu trition and health: an overview. Food Quality Pref. 9: 467 - 478.

Nix, S. (2009). Basic nutrition and diet therapy. $13^{\text {th }}$ edition. Elsevier publishers. Delhi.pp 188.201

Premala, P.V. and Mathew, S. (2012). Impact of a Pre-Game Meal on the Performance Level of Female Foot Ball Players. International Journal of Health Science and Research. 2: 59-71.

Punitha, V.C., Amudhan, A., Sivaprakasam, P. and Rathnaprabhu. V. (2014). Pocket Money: Influence on Body Mass Index and Dental Caries among Urban Adolescents. Journal of Clinical Diagn Research. 8(12): 10-12.

Richard, A.H., Champe, P.C. and. Ferrier, D.R. (2005).Sons. 365-81. Lippincotts Illustration Review. Lippincott Willaim Wilkin. 3rd Edn., pp: 355-358.

Vriendt, T. De, C. Matthys, W. Verbeke, I. Pynaert, S. De Henauw. (2009). Determinants of nutrition knowledge in young and middle-aged Belgian women and the association with their dietary behavior. Appetite., 52 (3): 788-792.

Warren, B. (2008). Food: The Key Concepts. http/www.bloomsbury.com/u $\mathrm{k} /$ food

WHO (2006). Adolescent Nutrition: A Review of the Situation in Selected South-East Asian Countries. http://apps.searo.who.int/PDS_DOCS/B 0239.pdf.

\section{How to cite this article:}

Shweta Joshi and Archana Kushwaha. 2019. Assessment of Direct and Indirect Factors Affecting the Nutrition Status of Hostel Girls in Pantnagar (India). Int.J.Curr.Microbiol.App.Sci. 8(08): 1034-1044. doi: https://doi.org/10.20546/ijcmas.2019.808.120 